\title{
Outcomes and Efficacy of Percutaneous Transluminal Renal Artery Angioplasty with Stent in Patients with Atherosclerotic Renal Artery Stenosis
}

\section{(1) Nuri Köse1, (1) Tarık Yıldırım²}

1Private Yücelen Hospital, Clinic of Cardiology, Muğla, Turkey

${ }^{2}$ Balıkesir University Faculty of Medicine, Department of Cardiology, Balıkesir, Turkey

\begin{abstract}
Objectives: Renal artery stenosis is the most common cause of secondary hypertension. The aim of this study is to evaluate the outcomes of percutaneous transluminal renal artery angioplasty and stenting (PTRAS) procedure for atherosclerotic renal artery stenosis (ARAS) which is the most common cause of secondary hypertension.
\end{abstract}

Materials and Methods: This retrospective chart review included 27 patients who had PTRAS procedure from 2012 to 2017. This procedure was performed to patients with ARAS whose luminal narrowing was $\geq 70 \%$. Successful intervention was accepted when the residual stenosis was $<20 \%$.

Results: The mean age of 27 patients with ARAS was $71.4 \pm 11.1$ years, and $55.6 \%$ were male. Most common indication for renal angiography was uncontrolled hypertension $(85.2 \%)$. PTRAS was indicated due to hypertension resistant to medical treatment in $92.6 \%$ of the patients. About $96.3 \%$ of the cases had hypertension. Renal artery stenosis was present on the right in 23 patients $(85.2 \%)$ and on the left in 20 patients $(74.1 \%)$. Bilateral renal artery stenosis was diagnosed in 16 patients (59.3\%). Predilatation was performed in nine cases $(33.3 \%)$ with right stenosis and in 10 cases (37\%) with left stenosis, and direct stenting was applied in seven (25.9\%) and six $(22.2 \%)$ of cases, respectively. The overall mortality rate was $22.2 \%$ during 5 -year follow ups. No other major events were noted.

Conclusion: PTRAS is associated with improved blood pressure control, renal functions, and survival, and it can be performed with high success and low complication rates. Nevertheless, each patient should be evaluated individually for the risks and benefits.

Keywords: Renal artery stenosis, renovascular hypertension, renal angioplasty, stent

Address for Correspondence: Nuri Köse, Private Yücelen Hospital, Clinic of Cardiology, Muğla, Turkey e-mail: drnurikose@hotmail.com ORCID: orcid.org/0000-0001-8658-2598

Received: 24.02.2020 Accepted: 27.07.2020

Cite this article as: Köse N, Yıldırım T. Outcomes and Efficacy of Percutaneous Transluminal Renal Artery Angioplasty with Stent in Patients with Atherosclerotic Renal Artery Stenosis. EJCM 2020;8(3):138-145.

DOI: 10.32596/ejcm.galenos.2020.11.057

${ }^{\circ}$ Copyright 2020 by Heart and Health Foundation of Turkey (TÜSAV) / E Journal of Cardiovascular Medicine published by Galenos Publishing House. 


\section{Introduction}

Atherosclerotic stenosis which is the most common primary renal artery disease is associated with many clinical syndromes including ischemic renal disease or hypertension. It is also a prevalent cause of secondary hypertension that is seen in $0.5 \%$ to $5 \%$ of all hypertensive patients $^{(1,2)}$. Renovascular hypertension, ischemic nephropathy and end-stage renal disease are among the probable outcomes of atherosclerotic renal artery stenosis (ARAS). The prevalence of renal artery stenosis was reported to be about $7 \%$ in the population over 65 years of age ${ }^{(1)}$. Also, the prevalence of renal artery disease was reported as $30 \%$ in patients who had renal artery angiography during cardiac catheterization for coronary artery disease and peripheral arterial disease. Among this population, severe obstructive renal artery stenosis was reported to be present in about $11-19 \%$ of the patients ${ }^{(2-4)}$. Other prevalence studies revealed that significant renal artery stenosis was present in $22-25 \%$ of patients with peripheral arterial disease, and bilateral disease was present in $44 \%$ of patients with renal artery stenosis ${ }^{(5)}$.

According to the currently available literature data, there is still a debate about the administration of percutaneous transluminal angioplasty with or without stenting to the patients with $\operatorname{ARAS}^{(6)}$. Despite the fact that numerous studies have suggested that percutaneous renal artery stent implantation (PTRAS) can resolve the ARAS and maintain a renal blood flow to retard the progression of nephropathy and renal insufficiency ${ }^{(7)}$, there are also numerous other studies that suggest resolution of vascular obstruction in ARAS does not result in improved renal function or blood pressure control compared to the patients that have received medical treatment alone ${ }^{(8)}$. Based on this background, this study aimed to evaluate the outcomes of PTRAS in our cases with ARAS to contribute to accumulating evidence for the ongoing research on this issue.

\section{Materials and Methods}

This study was conducted as a retrospective chart review at the Cardiology Department of Yücelen
Hospital in Muğla, Turkey, and included data of all ARAS patients that were treated with PTRAS at our clinic between February 2012 and December 2017. A total of 27 patients were included in the analyses. Routine patient assessment included demographic and clinical assessments, laboratory studies, and ultrasonography. Follow-up visits were performed at the $1^{\text {st }}, 3^{\text {rd }}, 6^{\text {th }}, 12^{\text {th }}$, $24^{\text {th }}, 36^{\text {th }}, 48^{\text {th }}$, and $60^{\text {th }}$ months after the procedure. A suitable sphygmomanometer was used for blood pressure measuring. Korotkoff phase 1 sound was accepted as systolic blood pressure and Korotkoff phase 5 sound was accepted as diastolic blood pressure. Blood pressure measurements were performed twice for each subject and their mean was used for statistical analysis. Estimated glomerular filtration rate (eGFR) was calculated using the MDRD formula.

Ethic approval for the study is obtained from the Clinical Research Ethical Board of Balıkesir University School of Medicine on 06.11.2019 with the number 2019/161.

\section{Diagnosis and Treatment}

All patients were diagnosed with luminal narrowing $\geq 70 \%$ by selective renal angiography before PTRAS. For the clinical assessments, unilateral stenosis was defined as an ostial stenosis without a stenosis in the contralateral renal artery, and bilateral stenosis was defined as either ostial stenosis on both renal arteries, a unilateral ostial stenosis with a contralateral occlusion, or solitary kidney with ostial stenosis. In-hospital major event was defined as progression of renal failure, acute surgery, acute occlusion, stroke, or death. Successful procedural intervention was defined as achieving a postprocedural narrowing lower than $20 \%$ and no in-hospital major events. Major events were also monitored during postprocedural 1-year period for increased medication need for blood pressure control, renal insufficiency, pulmonary edema, restenosis, and death.

For PTRAS administration, femoral, brachial or radial arterial punctures were performed using a $6 \mathrm{~F}-8 \mathrm{~F}$ sheath 
introducer, and a $0.34-0.38 \mathrm{~mm}$ guide wire for renal artery catheterization. After passage of guiding wire from the stenosis, a balloon-expandable stent was placed to resolve the stenosis. Intervention was accepted as successful if the residual stenosis was $<20 \%$. Preprocedural antiplatelet therapy was initiated at least one day prior to the intervention and continued for 3 months with $75 \mathrm{mg}$ clopidogrel daily, and also $100 \mathrm{mg}$ of aspirin indefinitely. A bolus dose of 5000 IU of heparin was also administered immediately before the procedure.

\section{Statistical Analysis}

Numerical data were presented as either mean and standard deviation or median and range, and categorical data were presented as frequency and percent. Comparisons between the dependent groups were done using the Friedman test for multiple groups and Wilcoxon test for two groups. A type-I error level of $5 \%$ was considered as the statistical significance level. All analyses were performed using SPSS 25 (IBM Inc., Armonk, NY, USA) software.

\section{Results}

The mean age of 27 patients with ARAS was $71.4 \pm 11.1$ years, and $55.6 \%$ were male. The mean body mass index was $28 \pm 3.4 \mathrm{~kg} / \mathrm{m}^{2}$, and five patients $(18.5 \%)$ were obese. The most common indications for renal angiography were uncontrolled hypertension (85.2\%) and hypertension with target organ damage (77.8\%). PTRAS was indicated due to hypertension resistant to medical treatment in $92.6 \%$ of the patients. The most common background diseases were hypertension (96.3\%), dyslipidemia (85.2\%), and chronic ischemic heart disease (70.4\%). General demographic and baseline characteristics of the patients were summarized in Table 1.

Renal artery stenosis was present on the right in 23 patients $(85.2 \%)$ and on the left in 20 patients (74.1\%). Bilateral renal artery stenosis was diagnosed in 16 patients (59.3\%). The mean percent of renal artery stenosis was $65.2 \%$ among cases with right stenosis (range 15\%-95\%) and $66.1 \%$ among cases with left stenosis (15-100\%).
Table 1. General demographic and baseline characteristics

\begin{tabular}{|c|c|}
\hline & Mean \pm S \\
\hline Age (years) & $71.4 \pm 11.1$ \\
\hline \multirow{2}{*}{ BMI $\left(\mathrm{kg} / \mathrm{m}^{2}\right)$} & $28 \pm 3.4$ \\
\hline & n (\%) \\
\hline \multicolumn{2}{|l|}{ Gender } \\
\hline Male & $15(55.6)$ \\
\hline Female & $11(40.7)$ \\
\hline Obesity & $5(18.5)$ \\
\hline \multicolumn{2}{|l|}{ Renal angiography indication } \\
\hline Uncontrolled hypertension & $23(85.2)$ \\
\hline During coronary angiography & $21(77.8)$ \\
\hline Hypertension with target organ damage & $21(77.8)$ \\
\hline Unstable angina & $17(63)$ \\
\hline Recurrent pulmonary edema/congestive heart failure & $13(48.1)$ \\
\hline Deterioration of renal functions & 9 (33.3) \\
\hline Doppler USG findings & $9(33.3)$ \\
\hline CT/MRI findings & $2(7.4)$ \\
\hline Creatine elevation due to ACE-I/ARB & $1(3.7)$ \\
\hline \multicolumn{2}{|l|}{ PTRAS indication } \\
\hline Hypertension resistant to medical treatment & $25(92.6)$ \\
\hline Increased creatinine on antiplatelet treatment & $22(81.5)$ \\
\hline Increased creatinine on statin treatment & $22(81.5)$ \\
\hline Unstable angina & $16(59.3)$ \\
\hline CHF flush pulmonary edema & $14(51.9)$ \\
\hline Renal function impairment & $11(40.7)$ \\
\hline Multiple renal arteries & 7 (25.9) \\
\hline \multicolumn{2}{|l|}{ Background diseases } \\
\hline Hypertension & $26(96.3)$ \\
\hline Dyslipidemia & $23(85.2)$ \\
\hline Chronic ischemic heart disease & $19(70.4)$ \\
\hline Diabetes mellitus & $14(51.9)$ \\
\hline Prior $\mathrm{CABG}$ and/or $\mathrm{PCl}$ & $14(51.9)$ \\
\hline Congestive heart failure & $13(48.1)$ \\
\hline Chronic renal failure & $12(44)$ \\
\hline Peripheral artery disease & $8(29.6)$ \\
\hline Cerebrovascular disease & 7 (25.9) \\
\hline Flush pulmonary edema & $7(25.9)$ \\
\hline Smoking & $4(14.8)$ \\
\hline Aortic disease & $2(7.4)$ \\
\hline
\end{tabular}

BMI: Body mass index, USG: Ultrasonography, CT: Computed tomography, MRI: Magnetic resonance imaging, ACE-I: Angiotensin-converting-enzyme inhibitors, ARB: Angiotensin receptor blockers, PTRAS: Percutaneous transluminal renal artery angioplasty and stenting, CHF: Congestive heart failure, CABG: Coronary artery bypass graft surgery, PCl: Percutaneous Coronary Intervention, SD: Standard deviation, $n$ : Number 
The PTRAS procedure failed in one patient with $100 \%$ stenosis on the left renal artery, and remaining procedures were all completed successfully. The most common vascular accesses were from right femoral artery in both of right and left stenosis. Predilatation was performed in nine cases (33.3\%) with right stenosis and in 10 cases (37\%) with left stenosis, and direct stenting was applied in seven $(25.9 \%)$ and six (22.2\%) of cases, respectively. Only two patients (one right, one left) had hematoma as a complication, and none of the patients had an in-hospital major event. The characteristics of renal artery stenosis and PTRAS procedures were presented in Table 2.

The biochemical analyses during the hospital stay and follow-up period were summarized in Table 3. According to the comparisons between pre-procedure and postprocedure analyses, creatinine levels $(p=0.036)$ and platelet counts $(\mathrm{p}=0.018$ ) were found to be significantly decreased following the PTRAS, but other parameters were remained stable. All biochemical assessments were in stable levels during the follow-up periods.

The clinical examinations during follow-up period are shown in Table 4. The analyses revealed that eGFR $(\mathrm{p}=0.048)$ was significantly improved, and systolic $(p<0.001)$ and diastolic $(p<0.001)$ blood pressures were significantly decreased at postprocedural assessments when compared to preprocedural values. These improvements were stayed stable during follow-up period. Likewise, the number of antihypertensive drugs (angiotensin receptor blockers, angiotensin-convertingenzyme inhibitors, diuretics, calcium channel blockers, beta-blockers, alpha-blockers and central agonists) used was decreased right after the PTRAS procedure $(p<0.001)$ and remained thru the follow-up period.

The follow-ups were continued for 5 years. During this period, two patients were recorded to be dead at the $6^{\text {th }}$ month in the follow-up, and four patients were noted to be dead at the $36^{\text {th }}$ month in the follow-up. The overall mortality rate was $22.2 \%$ during 5 -year follow ups. No other major events were noted.
Table 2. General characteristics of renal artery stenosis and PTRAS procedures

Mean \pm SD

(\% Range)

Mean renal stenosis \%

Right

$65.2 \pm 25.6$ (15-95)

Left

$66.1 \pm 31.8(15-100)$

n (\%)

Renal stenosis localization

Right stenosis

Osteal

$21(77.8)$

Non-osteal

$2(7.4)$

Left stenosis

Osteal

$18(66.7)$

Non-osteal

$2(7.4)$

Bilateral stenosis

$16(59.3)$

PTRAS procedure

Vascular access

Right stenosis

Right femoral artery

$14(51.9)$

Left radial artery

$2(7.4)$

Right radial artery

$1(3.7)$

Right brachial artery

1 (3.7)

Left stenosis

Right femoral artery

7 (25.9)

Left radial artery

5 (18.5)

Right radial artery

$2(7.4)$

Right brachial artery

1 (3.7)

Bilateral femoral arteries

1 (3.7)

Medical treatment

1 (3.7)

Predilatation

Right

$9(33.3)$

Left

$10(37)$

Direct stenting

Right

7 (25.9)

Left

$6(22.2)$

Complication (hematoma)

Right

$1(3.7)$

Left

1 (3.7)

PTRAS: Percutaneous transluminal renal artery angioplasty and stenting, $S D$ : Standard deviation 
Table 3. Biochemical studies during treatment and follow-ups

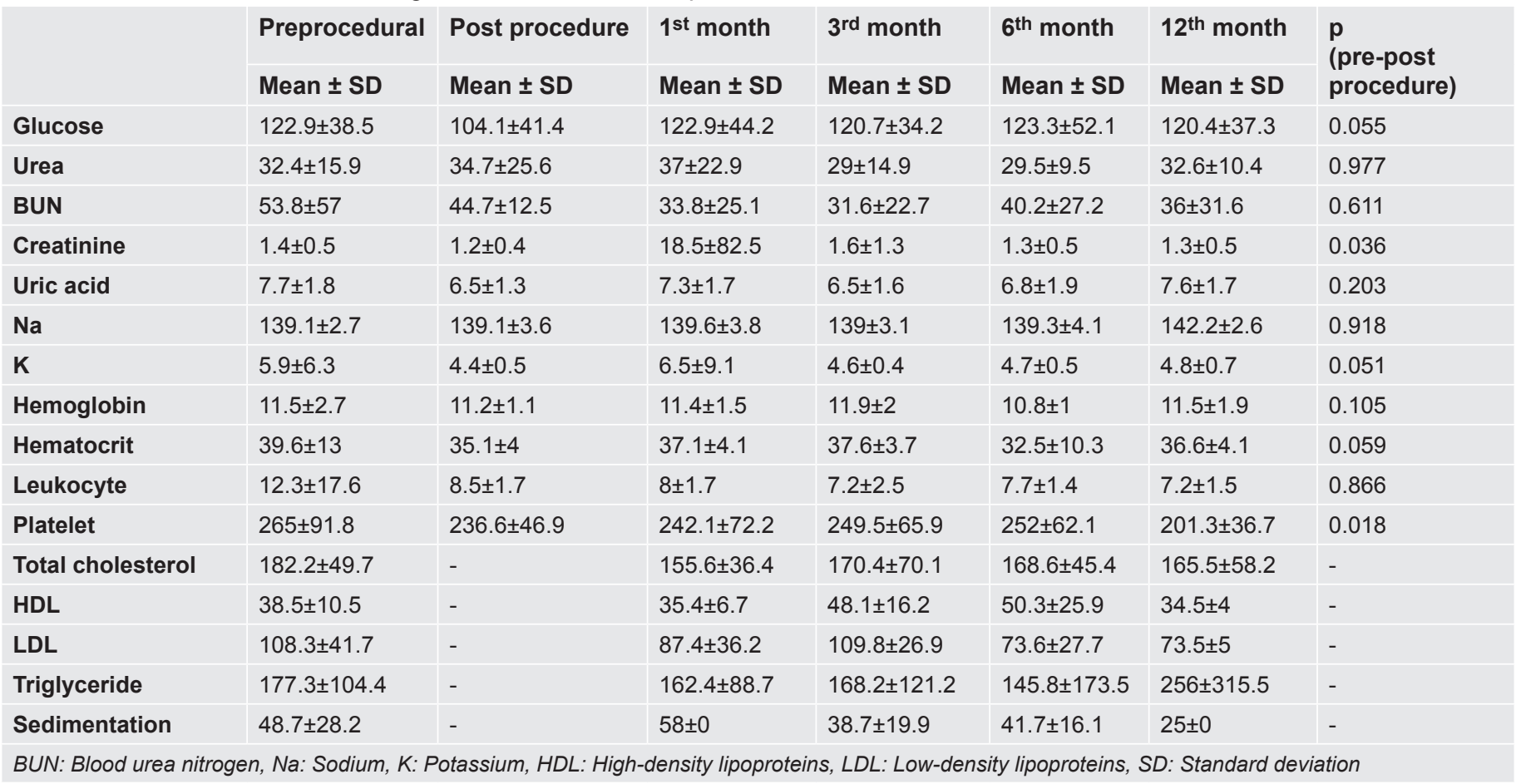

Table 4. Clinical examinations during follow-ups

\begin{tabular}{|c|c|c|c|c|c|c|c|}
\hline & Preprocedural & Post procedure & $1^{\text {st }}$ month & $3^{\text {rd }}$ month & $6^{\text {th }}$ month & $12^{\text {th }}$ month & \\
\hline & Mean \pm SD & Mean \pm SD & Mean \pm SD & Mean \pm SD & Mean \pm SD & Mean \pm SD & $\begin{array}{l}\text { procedure) } \\
\text { proced }\end{array}$ \\
\hline eGFR & $55.9 \pm 22.3$ & $65.3 \pm 24.9$ & $60.4 \pm 23.6$ & $60 \pm 20.3$ & $60.6 \pm 26.3$ & $57.5 \pm 19.1$ & 0.048 \\
\hline $\begin{array}{l}\text { Diastolic blood pressure } \\
(\mathrm{mmHg})\end{array}$ & $122.6 \pm 174.6$ & $78.9 \pm 9.5$ & $77.1 \pm 6.6$ & $80.6 \pm 5.3$ & $78.2 \pm 7.6$ & $81 \pm 6.7$ & $<0.001$ \\
\hline $\begin{array}{l}\text { Number of } \\
\text { antihypertensive drugs } \\
\text { used }\end{array}$ & $4(3-7)$ & $3(2-6)$ & $3(2-6)$ & $3(2-6)$ & $3(2-6)$ & $3(2-7)$ & $<0.001$ \\
\hline
\end{tabular}

\section{Discussion}

More than $90 \%$ of the renal artery stenosis cases are caused by atherosclerosis. In the atherosclerotic stenosis, the atherosclerotic plaque in the perirenal aorta extends to the osteal and proximal segments of main renal artery, and osteal and proximal involvement are commonly detected in ARAS $^{(9)}$. Also, ARAS is generally seen along with atherosclerosis in other localizations like the coronaries, carotid arteries, and peripheral arteries. The narrowness is mostly silent and associated with a widespread atherosclerotic process and diagnosed incidentally. But, when the stenosis reaches to critical levels $(>60-70 \%)$, renal perfusion decreases significantly and consequences like renovascular hypertension, resistant/malign hypertension, recurrent flash pulmonary edema and/or 
renal failure may occur. Meanwhile, the frequency and severity of other cardiovascular events also increase in patients with renal artery stenosis. Other indicators for high-risk disease include multivessel coronary artery disease, peripheral vascular disease, azotemia, resistant hypertension and flash pulmonary edema ${ }^{(10)}$.

The renal artery stenosis is seen more frequently due to the advances in vascular imaging methods and frequent use of these applications, increased incidence of atherosclerosis, and increased proportion of elderly patients in the population. Meanwhile, the advances in the percutaneous balloon angioplasty and/or stenting treatments have enhanced the interventions to renal artery stenosis and provided these methods to be applied to much more patients. Treatment of the stenosis by stent application is being administered for a long time; nevertheless, there is still an ongoing debate about whether there is a difference regarding vascular events and renal functions between stenting and medical treatment alone. PTRAS method can be performed with low risk and high success rates (98-100\%), and long-term patency can be achieved in about $95-98 \%$ of the $\operatorname{cases}^{(11-16)}$. However, the risk of nephrotoxicity due to the contrast use during stenting and the risk of atheroembolic renal disease due to vascular intervention should always be monitored for each case.

Several randomized trials have compared the stenting against medical treatment for the treatment of renal artery stenosis. The Dutch Renal Artery Stenosis Intervention Cooperative trial was conducted to compare renal angioplasty with antihypertensive medication in 106 patients with renal artery stenosis and hypertension, and reported that deteriorations in blood pressure control or renal artery occlusion was less observed in the PTRAS group ${ }^{(17)}$. Another study, which has compared the stenting plus medical therapy with medical treatment only (the medical treatment included antihypertensives, statins and aspirin) in patients with ARAS and impaired renal function, suggested that stenting should be avoided and treatment choice should be focused on a conservative approach for cardiovascular risk factor management ${ }^{(18)}$. Another study randomized 806 patients with ARAS to stenting plus medical therapy or medical therapy alone, and reported that revascularization has no benefit over medical treatment ${ }^{(19)}$. Nevertheless, major limitation of this study was the exclusion of the patients in need for revascularization, who had flash pulmonary edema or acute renal failure due to renal artery stenosis, and these patients were the candidates who should benefit from revascularization most. Another study, the HERCULES trial, evaluated the safety and effectiveness of renal artery stenting in patients with uncontrolled hypertension and ARAS, and reported that significantly decreased systolic blood pressure, low in-stent restenosis and complication rates were observed following PTRAS ${ }^{(20)}$. The largest randomized study to compare the medical therapy plus renal-artery stenting with medical therapy alone in patients with ARAS and either systolic hypertension or chronic kidney disease was the Cardiovascular Outcomes in Renal Atherosclerotic Lesions (CORAL) trial, and according to the results of this trial, there was no significant clinical benefit associated with renal artery stenting over multifactorial medical therapy ${ }^{(21)}$. Using the dataset from the CORAL trial, Murphy et al. ${ }^{(22)}$ conducted a post-trial exploratory study to evaluate whether subgroups of patients could benefit from renal artery stenting, but no evidence was found regarding stenosis severity, and systolic blood pressure elevation or magnitude of the trans-stenotic pressure gradient was associated with the outcomes.

Based on the currently available literature, revascularization for ARAS should be applied to only selected cases. The medical treatment is generally preferred for patients with renal dimensions $<8 \mathrm{~cm}$, resistivity index $>0.8$ in Doppler ultrasonography, serum creatinine levels $>3 \mathrm{mg} / \mathrm{dL}$, proteinuria $>1 \mathrm{gr} /$ day, and unilateral stenosis ${ }^{(11,23,24)}$. On the other hand, patients that would benefit from revascularization are those in whom 
blood pressure control cannot be achieved with adequate medication, those with accelerated hypertension and severe stenosis, those with rapid and progressive deterioration of renal functions under antihypertensive treatment, those with bilateral stenosis, those with serum creatinine levels of $1.5-3 \mathrm{mg} / \mathrm{dL}$ and glomerular filtration rate below $40 \%$ with unilateral stenosis, those who develops renal failure with angiotensin-converting enzyme inhibitors or angiotensin receptor blockers, and those with recurrent acute pulmonary edema or heart failure. The angioplasty procedure should be applied carefully in these patients, and renal functions should be monitored closely ${ }^{(11,23,24)}$.

\section{Conclusion}

Patients with ARAS generally have widespread systemic atherosclerotic disease and are prone to high rates of cardiovascular ischemic event risk during followups. The PTRAS procedure can be performed with high success and low complication rates in patients with ARAS. Nevertheless, the mortality is still high in ARAS patients despite successful treatment. Deaths are generally due to cardiovascular disease. However, PTRAS is associated with improved blood pressure control, renal functions, and survival. Patients should be evaluated carefully for PTRAS, and risk-benefit assessment should be carried out for each patient individually.

\section{Ethics}

Ethics Committee Approval: Ethic approval for the study is obtained from the Clinical Research Ethical Board of Balikesir University School of Medicine on 06.11.2019 with the number 2019/161.

Informed Consent: Informed consent form was obtained from each patient.

Peer-review: Externally peer-reviewed.

\section{Authorship Contributions}

Surgical and Medical Practices: N.K., Concept: N.K., T.Y., Design: N.K., T.Y., Data Collection or Processing: N.K., T.Y., Analysis or Interpretation: N.K., T.Y., Literature Search: T.Y., Writing: N.K.
Conflict of Interest: No conflict of interest was declared by the authors.

Financial Disclosure: The authors declared that this study received no financial support.

\section{References}

1. Hansen KJ, Edwards MS, Craven TE, et al. Prevalence of renovascular disease in the elderly: a population-based study. J Vasc Surg 2002;36:44351.

2. Harding MB, Smith LR, Himmelstein SI, et al. Renal artery stenosis: prevalence and associated risk factors in patients undergoing routine cardiac catheterization. J Am Soc Nephrol 1992;2:1608-16.

3. Weber-Mzell D, Kotanko P, Schumacher M, Klein W, Skrabal F. Coronary anatomy predicts presence or absence of renal artery stenosis. A prospective study in patients undergoing cardiac catheterization for suspected coronary artery disease. Eur Heart J 2002;23:1684-91.

4. Jean WJ, al-Bitar I, Zwicke DL, Port SC, Schmidt DH, Bajwa TK. High incidence of renal artery stenosis in patients with coronary artery disease. Cathet Cardiovasc Diagn 1994;32:8-10.

5. Rimmer JM, Gennari FJ. Atherosclerotic renovascular disease and progressive renal failure. Ann Intern Med 1993;118:712-9.

6. de Leeuw PW, Postma CT, Spiering W, Kroon AA. Atherosclerotic Renal Artery Stenosis: Should we Intervene Earlier? Curr Hypertens Rep 2018;20:35.

7. Hu Y, Zhang Y, Wang H, et al. Percutaneous renal artery stent implantation in the treatment of atherosclerotic renal artery stenosis. Exp Ther Med 2018;16:2331-6

8. Chade AR. Understanding and managing atherosclerotic renovascular disease: still a work in progress. F1000Res.2018;7:F1000.

9. Safian RD, Textor SC. Renal-artery stenosis. N Engl J Med 2001;344:431-42.

10. White CJ. Screening renal artery angiography at the time of cardiac catheterization. Catheter Cardiovasc Interv 2003;60:295-6.

11. Bokhari SW, Faxon DP. Current advances in the diagnosis and treatment of renal artery stenosis. Rev Cardiovasc Med 2004;5:204-15.

12. Olin JW. Renal artery disease: diagnosis and management. Mt Sinai J Med 2004;71:73-85.

13. Lederman RJ, Mendelsohn FO, Santos R, Phillips HR, Stack RS, Crowley JJ. Primary renal artery stenting: characteristics and outcomes after 363 procedures. Am Heart J 2001;142:314-23.

14. Leertouwer TC, Gussenhoven EJ, Bosch JL, et al. Stent placement for renal arterial stenosis: where do we stand? A meta-analysis. Radiology 2000;216:78-85

15. Blum U, Krumme B, Flügel P, et al. Treatment of ostial renal-artery stenoses with vascular endoprostheses after unsuccessful balloon angioplasty. N Engl J Med 1997;336:459-65.

16. Klinge J, Mali WP, Puijlaert CB, Geyskes GG, Becking WB, Feldberg MA Percutaneous transluminal renal angioplasty: initial and long-term results. Radiology 1989;171:501-6. 
17. van Jaarsveld BC, Krijnen P, Pieterman H, et al. The effect of balloon angioplasty on hypertension in atherosclerotic renal-artery stenosis. Dutch Renal Artery Stenosis Intervention Cooperative Study Group. N Engl J Med 2000;342:1007-14.

18. Bax L, Woittiez AJ, Kouwenberg HJ, et al. Stent placement in patients with atherosclerotic renal artery stenosis and impaired renal function: a randomized trial. Ann Intern Med 2009;150:840-8.

19. ASTRAL Investigators, Wheatley K, Ives N. Revascularization versus medical therapy for renal-artery stenosis. N Engl J Med 2009;361:1953-62.

20. Jaff MR, Bates M, Sullivan T, et al. Significant reduction in systolic blood pressure following renal artery stenting in patients with uncontrolled hypertension: results from the HERCULES trial. Catheter Cardiovasc Interv 2012;80:343-50.
21. Cooper CJ, Murphy TP, Cutlip DE, et al. Stenting and medical therapy for atherosclerotic renal-artery stenosis. N Engl J Med 2014;370:13-22.

22. Murphy TP, Cooper CJ, Matsumoto AH, et al. Renal Artery Stent Outcomes: Effect of Baseline Blood Pressure, Stenosis Severity, and Translesion Pressure Gradient. J Am Coll Cardiol 2015;66:2487-94.

23. Uder M, Humke U. Endovascular therapy of renal artery stenosis: where do we stand today? Cardiovasc Intervent Radiol 2005;28:139-47.

24. Mailloux LU. Atherosclerotic ischemic renal vascular disease: do published outcomes justify the overzealous diagnostic approaches? Semin Nephrol $2003 ; 23: 278-82$ 